Revista Aspas

ppgac - USP

Artigo

\title{
ESTADO E FINANCIAMENTO TEATRAL: APONTAMENTOS PARA UMA PERSPECTIVA \\ CLASSISTA
}

STATE AND THEATRICAL FUNDING: NOTES FOR A CLASS PERSPECTIVE

ESTADO E FINANCIAMENTO TEATRAL: NOTAS PARA UMA PERSPECTIVA CLASISTA

Fernando Bustamante

Fernando Bustamante

Doutorando pela FFLCH/USP. Pesquisa em andamento com conclusão em 2022. Estudos Linguísticos e Literários em Inglês sob orientação da Profa. Dra. Maria Silvia Betti. Bolsista CAPES. 


\section{Resumo}

Resgatando brevemente algumas experiências de movimentos teatrais vinculados à classe trabalhadora ou a uma perspectiva popular e de oposição aos valores da classe dominante e do capitalismo, tanto internacionalmente como no Brasil - remontando a genealogia desses movimentos desde o Théâtre Libre de Antoine ao movimento Arte contra a Barbárie do teatro de grupo em São Paulo - o artigo procura discutir como o financiamento estatal a tais iniciativas constitui necessariamente momentos de exceção que, pela própria natureza do Estado capitalista, não podem se sustentar, e aponta a perspectiva da vinculação ao movimento operário organizado como a forma capaz de fomentar tal tipo de produção teatral.

Palavras-chave: Teatro e financiamento público; Teatro e Estado; Teatro contra-hegemônico; Teatro e capitalismo; Teatro operário.

\section{Abstract}

Briefly discussing some historical experiences of theatrical movements linked to the working class or to a popular perspective opposed to the ruling class and capitalist values, both internationally and in Brazil - retracing its genealogy from Antoine's Théâtre Libre to the Arte contra a Barbárie movement of the theatre groups in São Paulo - the article aims to discuss that the state funding of such initiatives is necessarily exceptional and, due to the nature of the capitalist State itself, is unable to be sustained for long periods. Points out to the perspective of an organic binding to the working class organized movement as the solution for fostering such theatrical production.

Keywords: Theatre and public funding; Theatre and State; Counterhegemonic theatre; Theatre and capitalism; Worker's theatre.

\section{Resumen}

Rescatando brevemente algunas experiencias de movimientos teatrales vinculados a la clase trabajadora o a una perspectiva popular y de oposición a los valores de la clase dominante y el capitalismo, tanto internacionalmente como en Brasil, rastreando la genealogía de estos movimientos desde el Théâtre Libre de Antoine hasta el movimiento Arte contra a Barbárie del teatro grupal en São Paulo, el artículo busca discutir cómo la financiación estatal para tales iniciativas constituye necesariamente momentos de excepción que, por la naturaleza misma del estado capitalista, no puede sostenerse de forma duradera, y apunta a la 
perspectiva de vincularse con el movimiento obrero organizado como la forma capaz de fomentar tal producción teatral.

Sou como soca de cana, me cortem que eu nasço sempre.

- Teatro Popular União e Olho Vivo

Quando os artistas se dizem "profissionais" eu falo "bom, ou você é artista ou você é profissional". - Luiz Carlos Moreira, diretor e dramaturgo do Engenho

Teatral

A relação entre produção artística e condições materiais que a viabilizam remete à questão elementar: o que é arte e a que $(m)$ serve? Neste artigo retomaremos experiências históricas do teatro de tradição popular, operária e de esquerda para podermos tentar situar o debate no Brasil atual e esboçar problemas que se colocam aos que fazem uma produção cultural que, como mínimo, esteja "a contrapelo" da ideologia hegemônica.

\section{Um teatro fora do circuito da classe dominante}

A genealogia de um teatro dos trabalhadores, independente da classe dominante e seu Estado - com autofinanciamento como meio material para atingir o fim de renovação artística e ampliação do público às camadas populares - tem como marco o Théâtre Libre (Teatro Livre) de André Antoine, criado em 1887 na França. Em oposição à Comédie-Française, criada por Luís XIV em 1680, Antoine queria um teatro novo, e o estabelecimento da estética naturalista e do financiamento por meio de assinantes abriram portas para 0 surgimento de um teatro ligado aos trabalhadores.

Um dos teatros que segue o exemplo de Antoine é o Freie Bühne (Palco Livre), fundado em Berlim em 1889, que, por meio do sistema de assinaturas, leva à Alemanha o naturalismo, então rechaçado pelos teatros comerciais. Alguns dramaturgos ali encenados, como Hauptmann, Ibsen e Strindberg são apontados por Szondi como representantes da "crise do drama" (SZONDI, 2001). Sua duração efêmera, com três temporadas de atividades, é atribuída 
principalmente à adesão das companhias comerciais ao naturalismo, ofuscando a Freie Bühne.

Esses dois experimentos já demonstram que a busca por um financiamento independente ou alternativo ao circuito comercial hegemônico quase sempre está associada a uma renovação estética, tanto formal quanto no conteúdo. A mesma ambição podemos ver no caso russo, também influenciado por Antoine, do Московский Художественный академический театр, (Teatro de Arte de Moscou), criado por Stanislávski e NiemiróvitchDântchenco.

Dentre a constelação dos teatros livres inspirados em Antoine, um passo adiante foi dado pelo Freie Volksbühne (Palco Livre do Povo) alemão, cujo objetivo era levar as classes populares ao teatro. Quando se funde ao Neue Freie Volksbühne, em 1920, conta com 80 mil afiliados: "Em contraste com os organizadores do clube teatral, os sindicatos de Berlim viram o novo empreendimento como parte da luta de classes. Eles instintivamente reconheceram no novo teatro um bastião cultural de seu movimento". (PISCATOR, 1980, p. 32)

\section{Teatro operário de massas e teatro 'adulto, livre e sem censura': Rússia e EUA}

Duas experiências fundamentais devem ser resgatadas para pensarmos um teatro em escala de massas. A primeira é a soviética: após a Revolução de Outubro, artistas de vanguarda se unem ao Estado para difundir notícias da revolução. Em 1918, o teatro de agitação passa a receber suporte material e se irradia pelo país. Barcos e trens de agitprop se proliferam. Os grupos de 'blusas azuis' se multiplicam exponencialmente, chegando a 7 mil na Rússia. Atividade política e teatro de agitação, experimentalismo e formas tomadas do teatro popular se fundiam, fomentando debates teóricos. Maiakóvski, por exemplo, transitava entre artes plásticas, poesia, dramaturgia e cinema. É pioneiro da dramaturgia épica com seu Mistério-Bufo em celebração ao primeiro aniversário Revolução de Outubro. 
Experiência sem paralelo na história, o Estado operário fomentou criações artísticas em todos os âmbitos e espraiou sua influência pelo globo. Hallie Flanagan relatou a experiência nos EUA (FLANAGAN, 1929). Por meio dos trabalhadores imigrantes, como os que fundaram o Artef (Arbeiter Theater Verband), as experiências soviéticas e alemãs fincaram raízes nos EUA. Ali, como sintetizado por Elmer Rice: "[o teatro] não teve origens eclesiásticas, palacianas ou estatais; é inteiramente produto do empreendimento comercial e, durante os dois séculos de sua existência, tem sido dominado pelo empreendimento comercial" (RICE, 1962, p. 107). Enquanto na Europa a questão fundamental por vezes era a criação de um teatro capaz de ser independente do Estado, nos EUA o teatro nasce esmagado sob o peso da indústria cultural com o lucrativo business da Broadway. Independência econômica e renovação estética mais uma vez viriam lado a lado, junto ao crescimento do movimento operário. Dois movimentos surgiram: os "little theatres" (teatrinhos), impulsionados pela boemia intelectual de Greenwich Village; e o teatro operário, ligado aos grupos de imigrantes, que encontrou seu caminho de desenvolvimento ligado ao Partido Comunista.

O 'toque de Midas' do capitalismo, que transforma tudo o que encosta em mercadoria, logo faria seu trabalho: "pouco mais de doze anos depois, o idealismo pioneiro do movimento dos little theatres havia cedido seu lugar a um complexo de 'sucesso'" (BLAKE, 1962, p. 6). Quanto ao teatro operário, a cooptação por meio da comercialização seria inviável, já que era motivado como na Rússia ou Alemanha - pela militância de uma classe em pé de guerra contra o capitalismo. A sua cooptação se daria pela política de solapar a independência de classe oriunda do Partido Comunista já stalinizado, que influenciou o movimento para que caísse sob a influência do governo Roosevelt. Como parte do New Deal, com sua política keynesiana de combate à crise econômica, surge o Federal Theatre Project (FTP), definido por Roosevelt como um "teatro livre, adulto e sem censura". Hallie Flanagan dirigiu - FTP, imprimindo a influência da experiência soviética, mas com uma diferença fundamental: era um Estado capitalista, e não operário que o bancava. 
O FTP chegou a empregar 12.700 pessoas. Contudo, o preço a se pagar pelo financiamento do Estado capitalista era a perda da autonomia política e criativa. O primeiro episódio a mostrar isso é a censura da peça Ethiopia, que marcou a ruptura de Elmer Rice com o FTP. A abrangência dessa cooptação se mostra em que, após o FTP ser encerrado por ordem do Congresso com a House of Un-American Activities Committee (HUAC), o teatro operário se vê devastado; substituindo a estrutura independente e militante do período anterior pela estrutura estatal do FTP, os artistas haviam perdido a independência e, com o fim do programa estatal, ficaram à míngua.

\section{Teatro independente na periferia capitalista}

No Brasil - diferente dos EUA, onde o teatro se tornou um lucrativo negócio - até empreendimentos comerciais sobreviviam a duras penas, como demonstra a história do Teatro Brasileiro de Comédia (TBC). A busca por uma alternativa autossustentável também se casou com a renovação da forma e dos temas na confluência que ocorreu no Teatro de Arena, que demarcou sua identidade própria, bem como sua possibilidade de ser um empreendimento viável, com a estreia de Eles não usam Black Tie, de Gianfrancesco Guarnieri, em 1958.

Também se origina aí a busca de artistas para se ligar ao movimento de massas. Sob influência de membros do PCB - em primeiro lugar Oduvaldo Vianna Filho - aqui o agitprop já nasce atrelado a um projeto de conciliação de classes - denominado de 'nacional e popular' - com o apoio às reformas de base do governo nacional-desenvolvimentista de João Goulart. Outra particularidade era a ausência de ligação aos sindicatos, substituída pelo movimento estudantil por meio da UNE¹. A inspiração para o Centro Popular de Cultura (CPC), além do teatro operário europeu, vinha também do Movimento de Cultura Popular (MCP) de Pernambuco. Ali, contudo, a autonomia não existira desde a origem: o MCP era vinculado ao governo de

1 Exceções dignas de nota são o CPC de Santo André e o Grupo Forja, esse já nos anos 1970. 
Miguel Arraes. Era, assim, politicamente atrelado e financeiramente dependente do governo.

Já o CPC não era um braço do governo, ainda que o apoiasse politicamente, e precisava encontrar financiamento independente. De acordo com Carlos Estevam Martins, o CPC se estruturou como uma empresa prestadora de serviços para obter recursos financeiros (BERLINCK, 1984, p. 17). Mas, na prática, muitos recursos vinham do Estado, com o qual o CPC mantinha relação de apoio político, militando em defesa das reformas de base de Jango, como na UNE Volante e com peças como o Auto dos $99 \%$. Segundo Paiva (BERLINCK, 1984, p. 18), ○ CPC sobrevivia com contribuições individuais esparsas até obter, em dezembro de 1961, "um auxílio de Cr\$ 3.000"2, utilizado para a gravação do filme Cinco Vezes Favela e do LP O povo Canta, com tiragem de 11 mil exemplares. Um relatório do CPC de 1964 aponta para um orçamento de $\mathrm{Cr} \$ 4.500 .000$ para o filme (CPC, 1964); um artigo no Jornal do Brasil indicava o valor de $\operatorname{Cr} \$ 6.000 .000$ (CARNEDUTO FILHO, 2008, p.84).

Pela escassa documentação, é impossível saber o valor exato, mas as cifras acima nos dão uma ideia aproximada ${ }^{3}$. Os custos do filme praticamente levaram à bancarrota o $\mathrm{CPC}$, como atesta a carta que o presidente da UNE, Aldo Arantes, escreveu às entidades estudantis pedindo que ajudassem a divulgar o filme:

\footnotetext{
Urge recuperar o capital investido, pois, embora o orçamento tenha sido o mais modesto já consumido numa produção brasileira, elevar-se-á a cerca de três milhões de cruzeiros. A necessidade de êxito comercial do empreendimento é mais intensa desde que se considere que desse êxito depende não só o prosseguimento das atividades cinematográficas do Centro Popular de Cultura (CPC) da UNE, como a própria manutenção do órgão, pois no referido filme gastou-se quase toda a verba de que se dispunha. (apud. CARNEDUTO FILHO, 2008, p.84)
}

20 número está incorreto, comparando com as demais cifras pode-se deduzir ser 3 milhões. $O$ mesmo se aplica à verba de Cr\$5.800.000 do SNT citada a seguir.

$3 \mathrm{Cr} \$ 4.500 .000 \mathrm{em}$ valores atuais, corrigido pelo índice IPC-SP (FIPE), segundo a calculadora do Banco Central, equivaleria a aproximadamente R\$188.110. 
A venda de $O$ Povo Canta manteve o CPC durante o ano seguinte, e então Cr\$5.800.000 foram obtidos com o Serviço Nacional de Teatro (SNT) para a construção do teatro na sede da UNE. As dificuldades financeiras impediram novos projetos. Outro aporte significativo só viria com o convênio firmado com o MEC para uma campanha de alfabetização de adultos, em 1963 (BERLINCK, 1984, p. 18). Esse mesmo convênio mostra a contradição da manutenção financeira atuando como 'sucursal' do Estado: os responsáveis pelo departamento de alfabetização acabaram se tornando funcionários do MEC e este foi fechado (BERLINCK, p. 20). Segundo Vinicius Brant, a carreta fora doação de um empresário e político brasileiro - não consta informação de quem seria e sob qual motivação -, e também havia recursos oriundos de shows pagos em comícios de políticos, bem como de pagamentos para apresentações em faculdades e sindicatos (BERLINCK, $p$. 18).

Como aponta o relatório do CPC de 1964, a questão financeira estava marcada desde sua origem, sendo um motivador para a confluência dos artistas que discutiam "seus problemas específicos de estrangulamento, de impossibilidade de trabalho, de marginalização", concluindo que era necessário "a formação de um organismo que unisse a todos e aumentasse $o$ poder de luta da intelectualidade brasileira" (CPC, 1964).

Ainda que o CPC tenha chegado a contar com um grau de profissionalismo que levou à criação da PRODAC - Produtora e Distribuidora de Arte e Cultura, que distribuía livros e discos produzidos pelo CPC e também de editoras como Civilização Brasileira, Fulgor e Universitária -, e que contasse até com funcionários remunerados, o que mantinha as atividades era fundamentalmente $\mathrm{o}$ ativismo de universitários, intelectuais e artistas que acreditavam em seu projeto político.

\section{O neoliberalismo e a luta por políticas públicas para a cultura}

Com advento do neoliberalismo, vigoram no âmbito das políticas de Estado para a cultura iniciativas como as Leis Sarney, Mendonça ou Rouanet: o Estado é um 'espectador' frente às empresas privadas, que, por meio de 
renúncia fiscal, atuam como curadoras de toda iniciativa cultural, transformando-as em marketing personalizado.

Exemplo fundamental da luta dos artistas contra esse processo é o movimento Arte contra barbárie e a sua conquista, a Lei do Fomento para Teatro da cidade de São Paulo, que constitui um caso paradigmático não apenas porque obteve o mais importante avanço, que, nos últimos 17 anos, levou a um florescimento sem precedentes dos grupos de teatro em São Paulo por fora do circuito comercial, com uma produção crítica e em aliança com movimentos sociais e regiões periféricas da cidade, mas também porque, frente ao momento atual de ataques às políticas públicas de cultura, é o que melhor mostra os limites da estratégia que pautou aquela luta.

Em meio à crise econômica, com ataques a direitos sociais e governos da direita à extrema-direita em todas as esferas, a Lei de Fomento foi embargada por meio de uma manobra jurídica cujo objetivo é, para além do corte nas verbas, o ataque à organização política dos coletivos de teatro de São Paulo reunidos na Cooperativa Paulista de Teatro, que agrega 787 coletivos teatrais (chegando a quase 900 coletivos no total) e mais de 4 mil artistas. Segundo seu presidente, Rudifran Pompeu:

\begin{abstract}
Nossa luta é também para defender um dos maiores equipamentos e forma de organização coletiva que dispomos, que é a Cooperativa Paulista de teatro. É a nossa instituição que é o alvo real dessa gente, é a nossa "entidade" que já enfrentou tantas e tantas lutas desde a ditadura militar que é o centro dessa questão. (TORRES, 2019)
\end{abstract}

Mesmo se a lei fosse integralmente cumprida, seu orçamento de $R \$$ 8,5 milhões representava aproximadamente $0,014 \%$ do orçamento de $R \$ 60,5$ bilhões previstos para 2019 em São Paulo. Assim, mais do que a motivação econômica, para o Estado se trata de um explícito ataque ideológico e político aos artistas, como ficou evidenciado no Projeto de Lei do vereador Fernando Holiday, que diz querer estabelecer mecanismos de "moralidade" na Lei de Fomento. Ele propõe que seja vedado qualquer projeto com "agenda política ou beneficiar de qualquer modo grupo político ou corrente ideológica" ou que 
"louve, apoie ou estimule (...) regimes hostis à liberdade e à democracia" e "radicalismos políticos" (HOLIDAY, 2019). Ou seja, trata-se de censura.

O desmonte do fomento já está afetando coletivos, obrigados a abandonar sedes e projetos. Para pensar o significado do ataque, retomamos fala de Iná Camargo durante ocupação da Funarte em 2011:

Quais são os pressupostos desta pauta "políticas públicas para cultura"? Primeiro pressuposto: é do interesse deste Estado que está aí a nossa existência e a arte que fazemos. Este pressuposto é falso. (...) Segundo pressuposto: a sociedade da qual este Estado é a expressão jurídica organizada está interessada em nós. Também é falso. (FALA, 2011)

A concepção que embasa a fala de Iná Camargo é a constatação feita por Marx e Engels no século XIX de que "O moderno poder de Estado é apenas uma comissão que administra os negócios comunitários de toda a classe burguesa." (MARX; ENGELS, 1848). Por outro lado, o Arte Contra a Barbárie se pautou em uma concepção distinta, retomada na recente carta do Movimento do Teatro de Grupo (MTG) de São Paulo:

\footnotetext{
Cultura é prioridade de Estado, por fundamentar o exercício crítico da cidadania na construção de uma sociedade democrática. [...] Para que o país encontre o caminho da promoção das humanidades e se afaste da barbárie, oficial e não-oficial, são necessárias medidas urgentes e concretas. Em nossa área, isso significa o fomento da produção artística continuada e comprometida com a formação crítica do cidadão. (Arte Contra a Barbárie apud. MOVIMENTO, 2019).
}

Todos os momentos que retomamos nesse artigo em que o Estado foi propulsor cultural (com exceção da Rússia revolucionária), este tinha à frente governos de caráter mais ou menos social-democratizante, em que um projeto de conciliação de classes estava em pauta e as organizações do movimento operário e/ou artistas se fizeram aliados dessa perspectiva. Também se mostrou que o caráter de classe do Estado capitalista faz com que essas iniciativas tenham uma vida necessariamente curta e um alcance limitado e, por outro lado, colocam os artistas como reféns dessas iniciativas, embotando-lhes as possibilidades de atuação independente. Alguns membros do Arte contra a Barbárie tinham essa consciência, como lembrava Iná 
Camargo em 2011: "Aprovada na Câmara [a Lei de Fomento], o Moreira avisava: temos que ficar espertos porque o poder vai meter a mão todas as vezes que puder e não vai sossegar enquanto não transformar essa lei no seu contrário." (ENSAIO, 2011).

A experiência do FTP, pela sua profundidade e envergadura, é a que melhor demonstra o potencial devastador da conciliação de classes e a consequente dependência dos artistas do Estado e de políticas reformistas de duração provisória. A semelhança da justificativa de Holiday para atacar o fomento às da HUAC para acabar com o 'comunista' FTP não é mera coincidência, mas uma declaração acabada do significado do Estado capitalista, tal como as declarações e medidas de Bolsonaro a respeito da Funarte e da Ancine.

Em 2012, ao tratar do mesmo tema, retomamos algo que Iná Camargo apresentava sobre o movimento dos Teatros Livres e o agitprop na Europa e Rússia, afirmando que

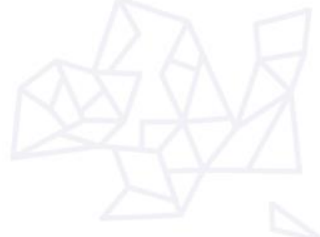

Os socialistas por toda a Europa, sobretudo os alemães, que começaram com a fórmula de Antoine, descobriram que, ampliando o número de associados, ao mesmo tempo que consolidavam a organização teatral, aumentavam de modo considerável o alcance do seu trabalho. O segredo de polichinelo desta estratégia era vincular-se ao próprio movimento de trabalhadores, sobretudo (mas não exclusivamente) aos seus partidos e sindicatos (...) (COSTA, 1996, p.72).

E alertávamos:

Essa tática de financiamento é uma forma de manter não apenas a independência política diante do Estado, mas também se preparar para o agravamento da crise econômica mundial e sua chegada ao Brasil, que levará a cortes drásticos no orçamento, em primeiro lugar em setores como a cultura (como demonstrado em 2011). Portanto, o financiamento independente do Estado torna-se cada vez mais uma questão de sobrevivência para os grupos. Não se trata de ser contra a luta por financiamento estatal, mas sim de atrelar essa à exigência do controle total das verbas por parte dos próprios artistas, ao mesmo tempo em que os trabalhadores da cultura devem procurar se ligar ao máximo às organizações de sua classe para garantir também sua independência estética e política diante da burguesia e de seu Estado que, no limite, nunca disponibilizará verbas para um teatro que faça diferença na luta contra sua existência (BUSTAMANTE, 2012) 
O momento de agravamento da crise econômica chegou, junto a governos de extrema-direita que possuem objetivos ideológicos ao atacar os artistas, com Bolsonaro querendo fazer das agências máquinas reacionárias de guerra cultural.

Por outro lado, a ligação dos artistas com o movimento operário se encontra dificultada pelo mesmo obstáculo que impede a classe trabalhadora de se organizar para barrar ataques a seus direitos, como a reforma da previdência: os sindicatos se tornaram máquinas de amortecimento dos choques de classe, dirigidos por burocracias que, em troca da manutenção de seus privilégios, estão dispostas a frear qualquer luta. O principal partido construído pela classe trabalhadora brasileira há muito já faz parte deste esquema. Frente a isso, alguns grupos recorrem a uma das poucas vias abertas entre artistas e movimento de massas, expressa pelo setor de cultura do MST. Mas, em que pese a sua política cultural mais progressista, a própria direção desse movimento se constituiu também como uma burocracia conciliadora muito parecida com as dos sindicatos, que contém as lutas pela terra, restringindo-as ao marco de pressões e negociações com governos, e apoiando o projeto político petista. A parceria acrítica dos artistas com esse movimento, portanto, corre um sério risco de dar apoio (consciente ou não) a essa política.

Os tempos são difíceis, e o auspício de uma nova recessão mundial sinaliza que se tornarão ainda mais. A disjuntiva que se coloca aos artistas é encarar seu ofício como uma profissão, procurando brechas no mercado onde possam vender sua força de trabalho em condições crescentemente precárias, ou assumir efetivamente sua arte como militância política, sabendo que essa se faz sob as circunstâncias mais adversas.

Em debate no TUSP, no lançamento da edição 8.2 da revista Aspas, o veterano Luiz Carlos Moreira, do Engenho Teatral, relatava sua surpresa frente a uma montagem na qual estava envolvido, e que foi abandonada pelos participantes após um pleito de verbas em programa público ser rejeitado. Outro veterano teatral, Roberto Ascar, também em debate no TUSP promovido pelo Teatro do Osso, expressou o mesmo tipo de inquietação, no sentido de que o 'costume' de receber as verbas do Estado tenha deixado 
acomodados os grupos. Em 2007, Sérgio de Carvalho apontava a mesma questão em relação ao fomento:

\begin{abstract}
Pouco a pouco, aquilo que era um meio para a conquista da autonomia e independência se torna um fim a ser obtido a qualquer custo. O crescimento da dependência dos recursos advindos do Estado tem feito com que muitos desses grupos canalizem suas energias políticas para a disputa por recursos públicos (CARVALHO, 2009, p. 163).
\end{abstract}

É fundamental reaprender com aqueles que, em meio a uma brutal ditadura, não apenas sem verbas, mas sob a mais férrea censura e perseguição policial, mantiveram ativo o front cultural de esquerda. Momentos de aguçamento da luta de classes tornam mais clara a perspectiva de que não pode existir uma arte que se oponha à ideologia da classe dominante e que, ao mesmo tempo, seja docilmente patrocinada pelo mesmo Estado que conduz os negócios dessa classe.

O Teatro União e Olho Vivo (TUOV), dirigido há 54 anos por César Vieira (pseudônimo que o advogado Idibal Pivetta adotou para driblar a censura da ditadura), é um exemplo de resistência: já em uma de suas primeiras peças, O Evangelho segundo Zebedeu, a leitura dramática no Teatro de Arena da Guanabara foi ameaçada com tiros e pedradas. O ano era 1968, um momento de endurecimento do regime. A tradição do TUOV deixou inclusive um vocabulário próprio de suas táticas de sobrevivência, como o 'capoeirismo cultural', tática de camuflar uma peça frente à repressão como os capoeiras camuflavam sua luta como dança; essa tática, aliás, foi usada pelo Arena durante os ensaios do Teatro Jornal: primeira edição para escapar à censura; no plano econômico, um dos termos legados pelo TUOV foi a 'tática Robin Hood', de montar peças pagas em teatros comerciais para juntar fundos visando a realização de peças gratuitas nos bairros periféricos. Já o Engenho Teatral, há anos sem nenhum tipo de patrocínio, realiza peças suas e de grupos parceiros em um teatro montado por seus esforços militantes ao lado do metrô Carrão, tendo sua última peça, Canção Indigesta, como um dos pontos de destaque da produção recente dos grupos de São Paulo (Cf. PARDAL, 2019). 
São exemplos inspiradores, pois, se o objetivo é realizar um teatro que se coloque como arma dos trabalhadores e setores oprimidos, deve-se ter consciência do que se enfrenta e para onde se ruma; quem são os aliados e inimigos. Comercialmente, o teatro só pode sobreviver como um instrumento de reprodução da ideologia dominante; e, se deseja seguir um rumo diverso, só poderá ser unindo seu destino ao da classe trabalhadora em sua luta contra a exploração. É preciso compreender profundamente e tornar viva uma velha palavra de ordem que falava justamente disso: "a independência da arte para a revolução. A revolução - para a liberação definitiva da arte" (BRETON; TROTSKI, 1985).

\section{Referências bibliográficas}

BERLINCK, M. T. O Centro Popular de Cultura da UNE. Campinas: Papirus Livraria Editora, 1984.

BLAKE, B. The Awakening of The American Theatre. New York City: Tomorrow Publishers, 1935.

BRETON, A; TROTSKI, L. Por uma Arte Revolucionária Independente. São Paulo: Paz e Terra, 1985.

BUSTAMANTE, F. A Luta dos Trabalhadores do Teatro. In: CONTRA A CORRENTE: REVISTA MARXISTA DE TEORIA, POLÍTICA E HISTÓRIA CONTEMPORÂNEA, n. 7, p. 81-86, 2012. Disponível em:

https://culturaemarxismo.wordpress.com/2012/10/16/a-luta-dos-trabalhadores-doteatro/

CARVALHO, S. Introdução ao Teatro Dialético. Experimentos da Companhia do Latão. São Paulo: Expressão Popular, 2009.

COSTA, I. C.. A hora do teatro épico no Brasil. São Paulo: Graal, 1996.

CPC. Documento original. 1964. Disponível em:

https://culturaemarxismo.files.wordpress.com/2012/03/documento-do-cpc-i.pdf. Acesso 19 jul. 2019.

CARNEDUTO FILHO, R. Discursos de intervenção: o cinema de propaganda ideológica para o CPC e o Ipês às vésperas do Golpe de 1964. ECA/USP. Dissertação de Mestrado, 2008. 
ENSAIO Aberto - Fomento ao Teatro. Coordenação de Fabiano Moreira. Direção: Luiz Gustavo Cruz. São Paulo: MPMIDIA, 2011. Disponível em: https://vimeo.com/showcase/1566267. Acesso 20 jul. 2019.

FALA de Iná Camargo em plenária 26/7/11. 1 vídeo (11 minutos). 2011. Disponível em: https://www.youtube.com/watch?v=qr6dXTN-Eoo. Acessado em 20 jul. 2019. HOLIDAY, F. Projeto de Lei 01-00458/2019. Diário Oficial do Município de São Paulo (DOM-SP) de 2 de Agosto de 2019, pg. 108. Disponível em: https://www.jusbrasil.com.br/diarios/254552872/dom-sp-normal-02-08-2019-pg108? ref=goto. Acesso 03 ago. 2019

FLANAGAN, H. Shifting Scenes of the Modern European Theatre. Londres: George G. Harrap, 1929.

MARX, K; ENGELS, F. Manifesto do Partido Comunista. 1848. Disponível em: https://www.marxists.org/portugues/marx/1848/ManifestoDoPartidoComunista/cap1. htm. Acesso em 20 jul. 2019.

MOVIMENTO de Teatro de Grupo de São Paulo. Carta aberta sobre a Lei de Fomento ao Teatro para a Cidade de São Paulo. 2019. Disponível em: https://docs.google.com/forms/d/e/1FAlpQLScWOIgJQiSdq6DjeFwGy9C7c3j_riwpc NFaJo3B5kl8CZ1kww/viewform. Acesso em 21 jul. 2019.

PARDAL, F. Digerir e pensar - a vida interditada no palco do Engenho Teatral. 2019. Disponível em: http://www.esquerdadiario.com.br/Digerir-e-pensar-a-vidainterditada-no-palco-do-Engenho-Teatral. Acesso 03 ago. 2019.

PISCATOR, E. The Political Theatre. Great Britain: Methuen drama, 1980.

RICE, E. Teatro Vivo. Rio de Janeiro: Fundo de Cultura, 1962.

SZONDI, P. Teoria do drama moderno. São Paulo: Cosac Naify, 2001.

TORRES, D. Chega de desmanche na cultura! Pelo fomento democrático! Esquerda Diário. 31 de agosto de 2018. Disponível em:

http://www.esquerdadiario.com.br/Chega-de-desmanche-na-cultura-Pelo-Fomentodemocratico. Acesso em 20 jul. 2019. 